\title{
In Situ Vapor-Deposited Parylene Substrates for Ultra-thin, Lightweight Organic Solar Cells
}

\author{
Joel Jean, Annie Wang, and Vladimir Bulović
}

Department of Electrical Engineering and Computer Science, Massachusetts Institute of Technology, Cambridge, MA 02139, USA

Email:*jjean@alum.mit.edu,aiwang@mit.edu,bulovic@mit.edu

\begin{abstract}
We fabricate the thinnest $(1.3 \mu \mathrm{m})$ and lightest $\left(3.6 \mathrm{~g} / \mathrm{m}^{2}\right)$ solar cells yet demonstrated, with weight-specific power exceeding $6 \mathrm{~W} / \mathrm{g}$, in order to illustrate the lower limits of substrate thickness and materials use achievable with a new processing paradigm. Our fabrication process uniquely starts with growth of an ultra-thin flexible polymer substrate in vacuum, followed by deposition of electrodes and photoactive layers in situ. With this process sequence, the entire cell — from transparent substrate to active layers to encapsulation — can be fabricated at room temperature without solvents and without breaking vacuum, avoiding exposure to dust and other contaminants, and minimizing damage risk associated with handling of thin substrates. We use in situ vapor-phase growth of smooth, transparent, and flexible parylene-C films to produce ultrathin, lightweight molecular organic solar cells as thin as $2.3 \mu \mathrm{m}$ including encapsulation with a second parylene-C film. These parylene-based devices exhibit power conversion efficiencies and fabrication yields comparable to glass-based cells. Flexible solar cells on parylene membranes can be seamlessly adhered to a variety of solid surfaces to provide additive solar power.
\end{abstract}

\section{Keywords}

Organic solar cell, substrate, lightweight, specific power, flexible, vapor deposition

\section{Introduction}

Solar photovoltaics (PV) are among the few low-carbon energy technologies capable of satisfying global electricity demand. Today's leading crystalline silicon (c-Si) and thin-film PV modules are low-cost, efficient, and reliable — but also rigid and heavy, up to $30 \mathrm{~kg}$ for a $300 \mathrm{~W}$ module. Restricted form factors exacerbate high balance-of-system (BOS) costs, which dominate PV system cost and hinder deployment. ${ }^{1,2}$ Lightweight, flexible solar cells are possible with emerging PV technologies, but only if lightweight, flexible substrates are used. In this work, we introduce a processing paradigm for producing thin, lightweight, clean, nanoscale-smooth, laminable, and flexible PV substrates and encapsulation layers: in situ vapor-phase deposition of transparent polymer films. 
The most common substrate material today is glass: It presents a flat, smooth, robust surface for cell processing and protects sensitive active materials from exposure to oxygen and water vapor. However, a rigid glass sheet dominates PV weight and thickness. For example, a typical organic, perovskite, or colloidal quantum dot solar cell is $600-900 \mathrm{~nm}$ thick and weighs $3-5 \mathrm{~g} / \mathrm{m}^{2}$, as shown in Fig. 1. In contrast, a typical glass substrate is $3 \mathrm{~mm}$ thick and weighs $\sim 8 \mathrm{~kg} / \mathrm{m}^{2}$, dwarfing the mass of the active layers and constraining specific power [W/g] for a given cell efficiency.
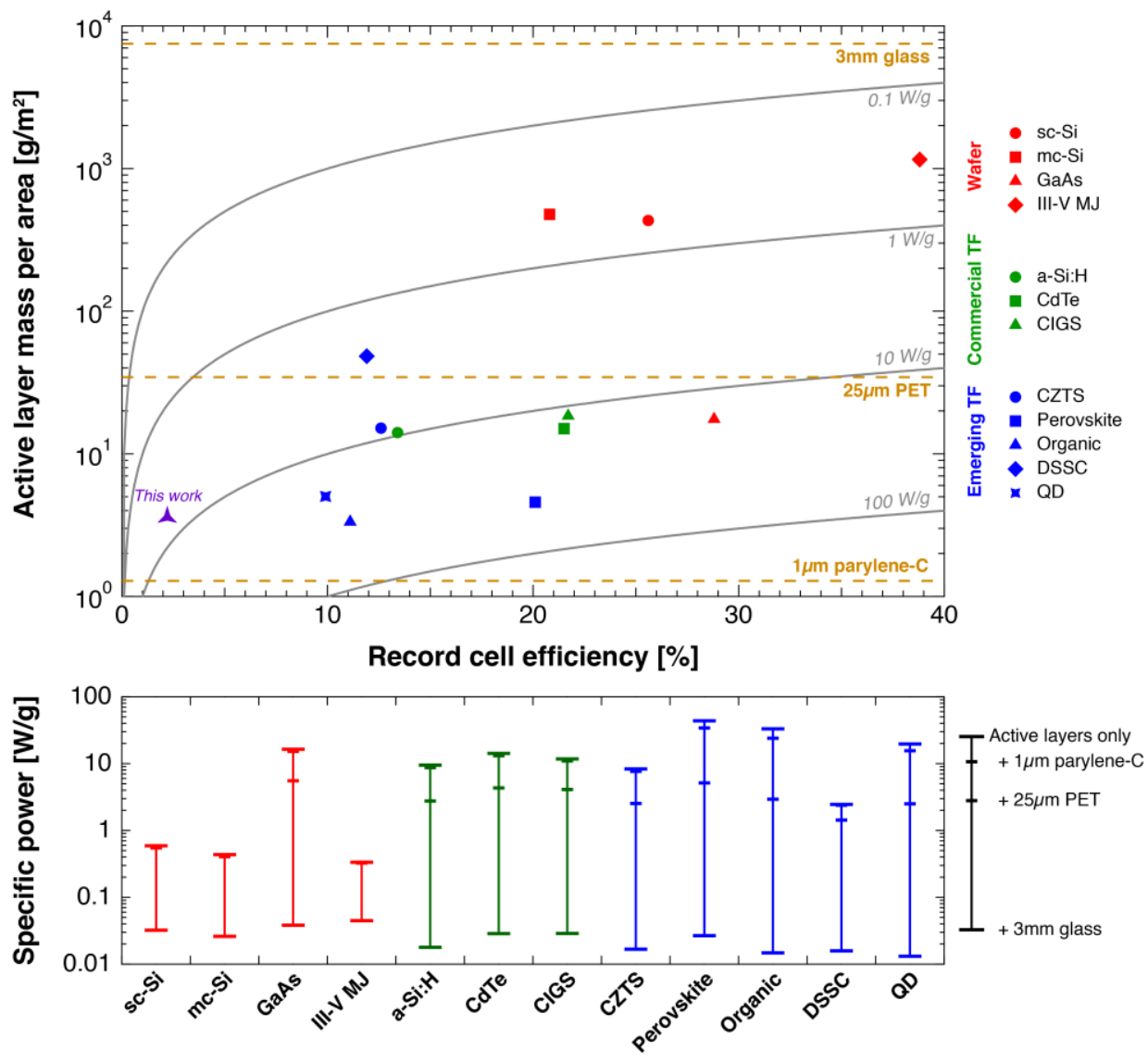

Fig. 1: Effect of substrates and active layers on $P V$ power-to-weight performance. In the top plot, typical mass per area (active layers including electrodes) vs. record power conversion efficiency is shown for all PV technologies. Dashed gold lines represent substrates: 3 mm-thick glass, $25 \mu \mathrm{m}$ PET, and 1 Mm parylene-C. Typical thick glass and plastic substrates dominate the weight of thin-film $(T F)$ cells. Specific power contours show that power-to-weight ratios are more sensitive to total cell weight per area than to power conversion efficiency. Emerging TF technologies are 2-3× less efficient but use 10-100× less active material than deployed technologies, allowing them to achieve higher specific powers by employing lightweight substrates. The purple marker represents the parylene-based cells from this work. In the bottom plot, specific power is shown for active layers alone and with various substrates. Device structures are described in Ref. 1.

\footnotetext{
* Wafer-based PV technologies include single-crystalline silicon (sc-Si), multicrystalline silicon (mc-Si), gallium arsenide (GaAs), and III-V multijunction (III-V MJ) PV. Commercial thin-film technologies include hydrogenated
} 
Plastics, textiles, and cellulosic materials are lightweight, flexible alternatives to glass. Organic solar cells have been demonstrated on polyethylene terephthalate (PET), ${ }^{3}$ polyethylene naphthalate (PEN), ${ }^{4}$ polyimide (PI) ${ }^{5}$ paper, ${ }^{6-8}$ and cellulosic substrates. ${ }^{9,10}$ In particular, PET and PEN allow scalable roll-to-roll processing and are produced commercially in high volumes. But thin PET and PEN substrates face several challenges intrinsic to their manufacture. Typically formed from bulk feedstock by extrusion and biaxial drawing, these films require additional packaging, transportation, cleaning, and surface preparation steps prior to device fabrication. Intrinsic and extrinsic surface defects are often unavoidable. Defect sizes range from below 200 $\mathrm{nm}$ to $10 \mu \mathrm{m}$ both laterally and vertically, ${ }^{11,12}$ presenting a major shorting risk for solar cells and other electronic devices with thin active layers. Planarizing overcoatings may help mitigate defects but add processing complexity. ${ }^{11}$ Furthermore, thin PET and PEN films are difficult to handle and expensive on both a per-weight and per-area basis.

Here we demonstrate an in situ, solvent-free, all-room-temperature process for fabricating organic solar cells on vapor-deposited parylene-C, which forms smooth, transparent films on a variety of surfaces. From substrate to active layers to encapsulation, solar cells are fabricated without breaking vacuum, thus minimizing contamination and damage risk associated with the transport and handling of ultra-thin substrates. Complete parylene-based devices released from a carrier wafer are the thinnest and lightest solar cells demonstrated to date (Fig. S14, SI).

\section{Materials and methods}

Materials: Parylene-C dimer (dichloro-[2,2]paracyclophane, diX-C) was purchased from Uniglobe Kisco. An indium zinc oxide (IZO; $\mathrm{In}_{2} \mathrm{O}_{3}$ with 10 wt.\% $\mathrm{ZnO}$ ) sputter target $(99.99 \%$ purity) was purchased from Idemitsu Corp. $\mathrm{MoO}_{3}$ (Alfa Aesar, 99.9995\%), tetraphenyldibenzoperiflanthene (DBP; Lumtec, >99\%), bathocuproine (BCP; Lumtec, >99\%), and Ag (Alfa Aesar, 99.999\%) were used as received. $\mathrm{C}_{60}(99.9 \%$, Sigma-Aldrich) was purified once by thermal gradient sublimation. ${ }^{13}$ Commercial PET and PEN films of varying thickness were obtained from Goodfellow.

Parylene substrate formation: Parylene-C films of varying thickness were deposited on borosilicate glass and on complete OPV devices in a custom-designed chamber. Glass and silicon substrates were cleaned by sonication in detergent, DI water, and acetone ( 5 min. each), followed by boiling in isopropanol twice for $5 \mathrm{~min}$. and $\mathrm{O}_{2}$ plasma treatment for $1 \mathrm{~min}$. Prior to parylene deposition, 1\% Micro-90 in DI water was spin-coated on glass at 2000 RPM for $60 \mathrm{~s}$ to form a release layer. Parylene deposition was carried out at a base pressure of $5 \mathrm{mTorr}$. diX-C dimer was sublimed at $90^{\circ}-120^{\circ} \mathrm{C}$ and cleaved in a pyrolysis furnace at $750^{\circ} \mathrm{C}$. Parylene-C films with thicknesses from $200 \mathrm{~nm}$ to $3 \mu \mathrm{m}$ were deposited at rates of up to $5 \AA / \mathrm{s}$ and monitored with a quartz crystal microbalance.

amorphous silicon (a-Si:H), cadmium telluride (CdTe), and copper indium gallium diselenide (CIGS). Emerging thin-film technologies include copper zinc tin sulfide (CZTS), perovskites, organic PV, dye-sensitized solar cells (DSSC), and colloidal quantum dot (QD) PV. 
Solar cell fabrication: Small-molecule organic solar cells were fabricated by standard vaporphase methods on parylene and glass substrates. IZO $(150 \mathrm{~nm})$ was deposited by RF-magnetron sputtering at a rate of between $0.4 \AA / \mathrm{s}$ and $0.8 \AA / \mathrm{s}$, Ar pressure of $6 \mathrm{mTorr}$, and RF power of 50 $80 \mathrm{~W} . \mathrm{MoO}_{3}(20-40 \mathrm{~nm}), \mathrm{DBP}(20 \mathrm{~nm}), \mathrm{C}_{60}(40 \mathrm{~nm}), \mathrm{BCP}(8 \mathrm{~nm})$, and Ag $(100 \mathrm{~nm})$ were thermally evaporated through a shadow mask at $1 \AA / s$, at a chamber base pressure of $10^{-6}$ Torr. The active area of $5.44 \mathrm{~mm}^{2}$ was determined by the overlap of the IZO and Ag electrodes. For encapsulation, an additional 1-3 $\mu \mathrm{m}$-thick parylene-C layer was deposited.

Characterization and testing: Transmission spectra were obtained using a Cary 5000 UV-VisNIR spectrophotometer. Refractive index and extinction coefficient spectra of all materials were extracted by fitting spectroscopic ellipsometry (SE) data obtained at $65^{\circ}, 70^{\circ}$, and $75^{\circ}$ angles of incidence using a Woollam variable-angle spectroscopic ellipsometer. No significant depolarization was observed. When characterizing organic samples, an atmospheric cell was used to maintain $\mathrm{N}_{2}$ atmosphere and avoid oxygen- and moisture-induced degradation. Sheet resistance was measured using a Jandel 4-point probe. J-V measurements were performed with a Keithley 6487 picoammeter, with $(100 \pm 10) \mathrm{mW} / \mathrm{cm}^{2}$ simulated solar illumination provided by a $150 \mathrm{~W}$ Newport $96000 \mathrm{Xe}$ arc-lamp equipped with an AM1.5G filter and diffuser. External quantum efficiency (EQE) spectra were measured without bias illumination. Atomic-force microscope (AFM) imaging was performed with an Agilent 5500 in tapping-mode operation.

\section{Results}

\subsection{Vapor-Deposited Parylene Substrates}

Among vapor-deposited polymers, parylene (poly-para-xylylene) has been most widely studied and deployed. ${ }^{14}$ Parylene variants with different dielectric, mechanical, and chemical properties are commercially available. ${ }^{15}$ This work focuses on parylene-C (poly-chloro-p-xylylene), the most common and low-cost variant. Parylene-C forms robust, conformal films at high deposition rates and is an excellent moisture barrier, with a reported water vapor permeability 5 times lower than PET_comparable to high-density polyethylene and superior to common barrier films. ${ }^{16}$

Parylene films are flexible, electrically insulating, stress-free, ${ }^{17}$ heat-moldable, ${ }^{18}$ chemically inert, ${ }^{15,19}$ smooth, and pinhole-free at thicknesses above $30 \mathrm{~nm} .{ }^{16}$ Fig. 2 shows AFM images of parylene-C on glass. The RMS roughness of $1 \mu \mathrm{m}$-thick parylene is $4.1 \pm 0.4 \mathrm{~nm}$, compared to $6.0 \pm 2.2 \mathrm{~nm}$ for $23 \mu \mathrm{m}$ PET and 10.3 $\pm 2.4 \mathrm{~nm}$ for $12 \mu \mathrm{m}$ PEN. Large dust particles and defects often observed on PET and PEN films (maximum heights of $61 \pm 31 \mathrm{~nm}$ and $140 \pm 63 \mathrm{~nm}$, respectively) are absent from parylene films (maximum height of $40 \pm 9 \mathrm{~nm}$ ). Parylene is highly transparent, with an average transmittance of $96 \%$ from $\lambda=350 \mathrm{~nm}$ to $\lambda=800 \mathrm{~nm}$ for film thicknesses below $5 \mu \mathrm{m}$ (Fig. 2a). 

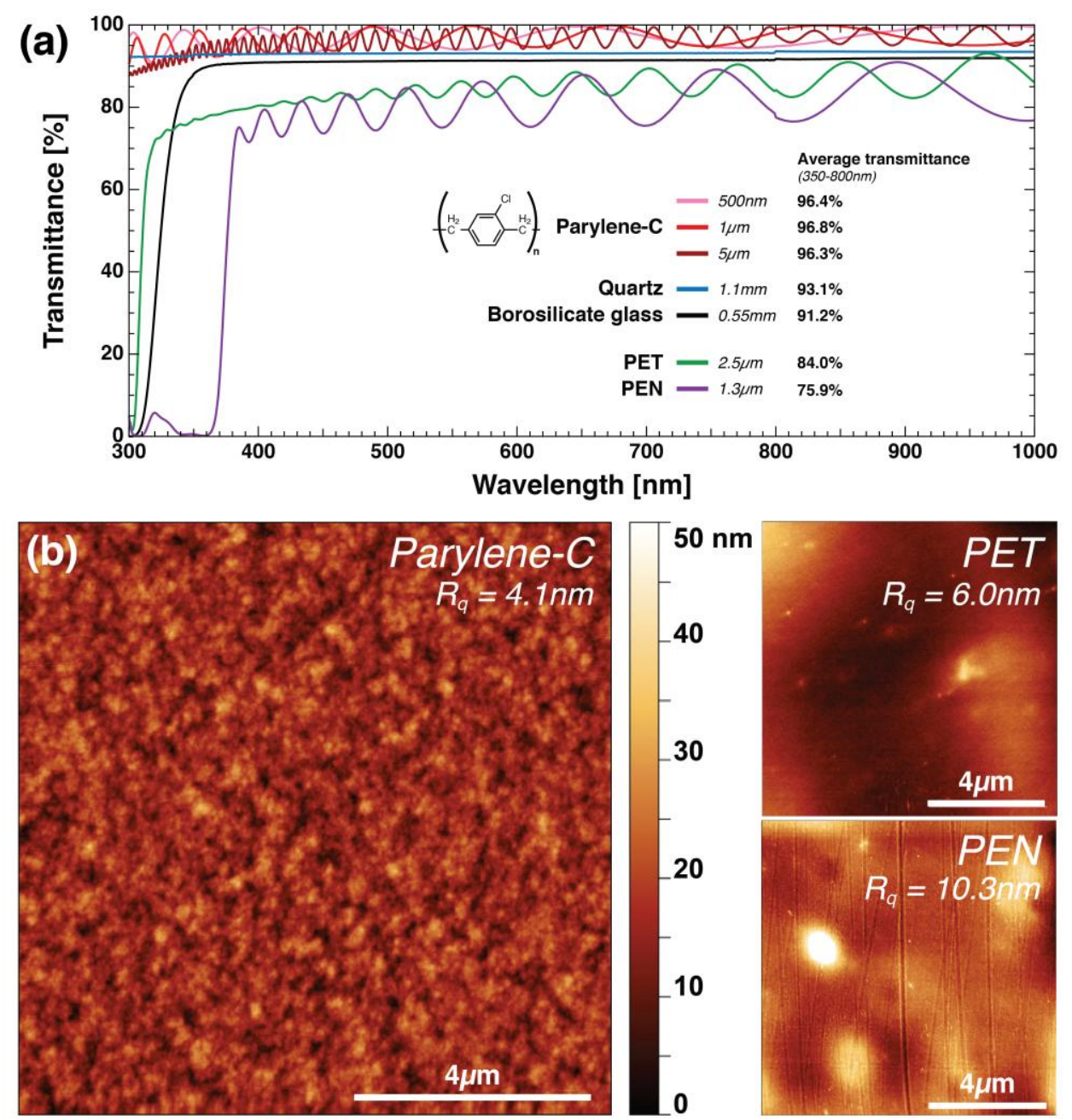

Fig. 2: Transparency and roughness of vapor-deposited parylene and other polymer substrates. (a) UV-vis transmission spectra of parylene-C, PET, and PEN films with thicknesses between $500 \mathrm{~nm}$ and $5 \mu \mathrm{m}$. Quartz and borosilicate glass are shown for reference. Parylene films are more transparent in the visible and NIR than PET and PEN films of similar thickness. (b) AFM images of parylene-C, PET, and PEN films. Parylene-C films exhibit the lowest RMS surface roughness.

Parylene-C films are typically deposited by pyrolytic polymerization. ${ }^{15,20}$ Thermal cleaving of the parylene dimer produces reactive monomer, which adsorbs and spontaneously polymerizes by chain growth on any surface below $90^{\circ} \mathrm{C} .{ }^{20}$ The resulting polymer is linear, polycrystalline with sub-micron domains, and of high molecular weight $(200,000-400,000 \mathrm{~g} / \mathrm{mol}){ }^{15,21}$ Film thicknesses from a few nanometers to tens of microns can be achieved at deposition rates of 10 $\AA / \mathrm{s}(17 \mathrm{~min} . / \mu \mathrm{m})$ or higher. During growth, samples remain at room temperature and under moderate vacuum of $1-10$ mTorr. ${ }^{15,20}$

In situ deposition of parylene-C onto a carrier produces a contaminant-free, transparent, insulating film that can serve as either a substrate or a buffer layer for subsequent device processing. Unlike solution-deposited materials such as polyimide, ${ }^{22}$ which typically require curing or annealing, room-temperature vapor-deposited parylene films require no post-deposition 
treatment. Active device layers can be deposited immediately by standard vapor-phase techniques, including evaporation, sputtering, or chemical vapor deposition (CVD). The complete device can then be encapsulated with parylene and the entire stack peeled off and laminated onto a variety of surfaces.

Any new substrate must be mechanically and chemically compatible with previously optimized device structures and fabrication processes. While metal and organic layers are easily deposited on flexible parylene membranes, ${ }^{23}$ finding a suitable transparent conducting electrode is more challenging. Key performance metrics are optical transparency and sheet resistance. Transparency is generally unaffected by flexing, but conductivity often suffers, especially for brittle electrode materials.

The most widely used transparent conductor today is tin-doped indium oxide (ITO). Sputterdeposited ITO films are commercially available and exhibit high visible transparency (92\%) and low resistivity $\left(290 \mu \Omega\right.$-cm) (Fig. S8, SI). However, ITO is brittle and cracks at low strains. ${ }^{24}$ When sputtered on parylene substrates, ITO films tend to buckle, forming networks of micronscale wrinkles over large areas $\left(>10 \mathrm{~mm}^{2}\right)$. This effect can be attributed to high compressive stress from thermal contraction of parylene after ITO deposition, as previously observed with ITO on polyester substrates. ${ }^{25,26}$

Unlike ITO, indium zinc oxide films sputtered on flexible parylene are smooth, with roughness of $1.9 \mathrm{~nm}$ compared to $0.4 \mathrm{~nm}$ on glass (Fig. S10, SI). IZO exhibits lower compressive stress than ITO when deposited at low pressures ( $<10$ mTorr $),{ }^{26,27}$ and amorphous IZO deposited by room-temperature RF sputtering is compatible with flexible polymer substrates and exhibits low resistivity when deposited at zero or near-zero oxygen partial pressures. ${ }^{28,29} \mathrm{We}$ find that amorphous IZO performs similarly to polycrystalline ITO as a transparent electrode for our organic solar cells. Film thickness and deposition parameters (e.g., oxygen flow rate and partial pressure, RF power, and deposition pressure) were optimized to minimize sheet resistance and maximize optical transmittance of IZO and ITO (Fig. S7-S9, SI). Transfer-matrix optical model predictions match experimental results and confirm a local maximum in transmittance for both IZO and ITO at a film thickness of $150 \mathrm{~nm}$. Optimized $150 \mathrm{~nm}$-thick IZO electrodes deposited at room temperature exhibit an average transmittance of $85 \%$ and a sheet resistance of $50 \Omega / \square$.

\subsection{Organic Solar Cells on Parylene}

Vapor-deposited low-molecular-weight organic materials are commonly used as photoactive layers for photovoltaic and light-emitting devices. We focus here on planar donor-acceptor heterojunction solar cells based on DBP and $\mathrm{C}_{60} \cdot{ }^{30,31}$ The parylene-based device structure and energy band diagram is shown in Fig. 3. Solar cell fabrication is performed entirely at room temperature in inert atmosphere or in vacuum. Sample transfer, shadow mask exchange, and all deposition steps from substrate to encapsulation can be carried out without exiting high vacuum (with base pressure of $10^{-6}$ Torr), guaranteeing an ultra-clean processing environment. 


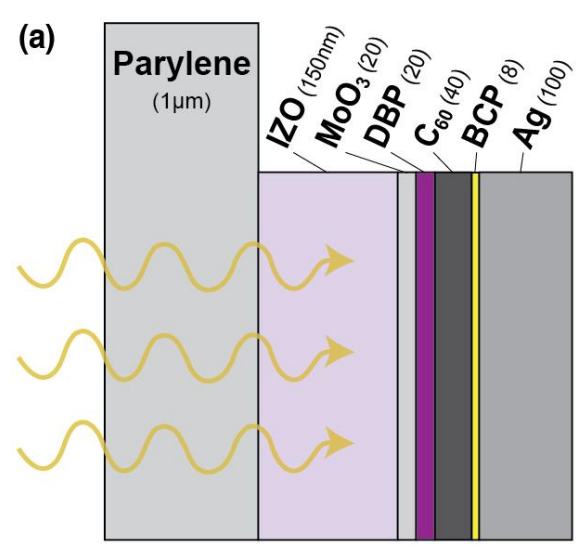

(b)

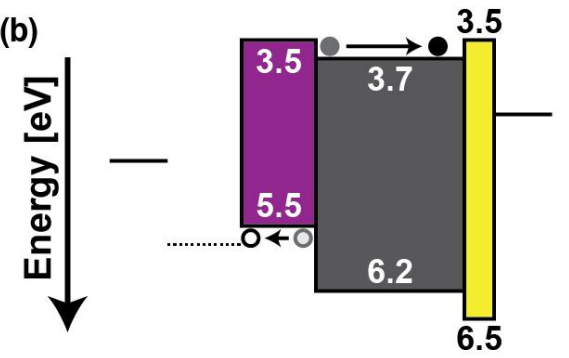

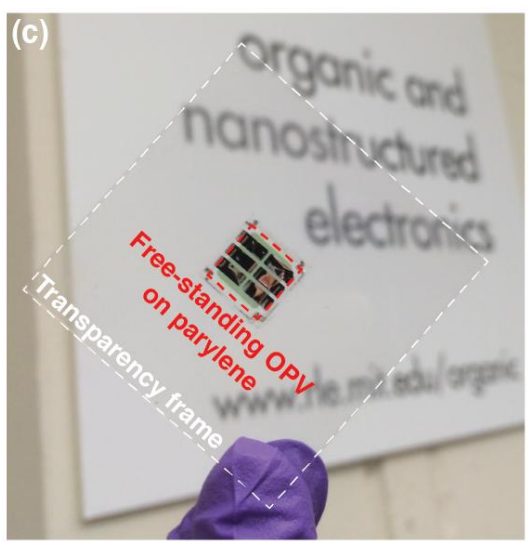

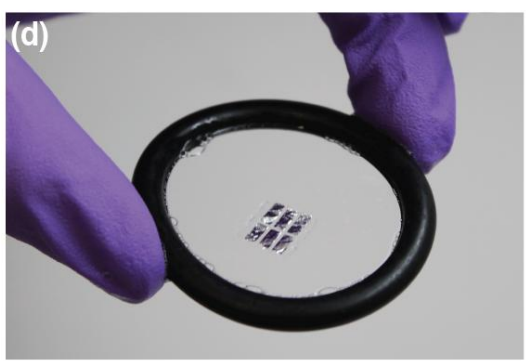

(e)

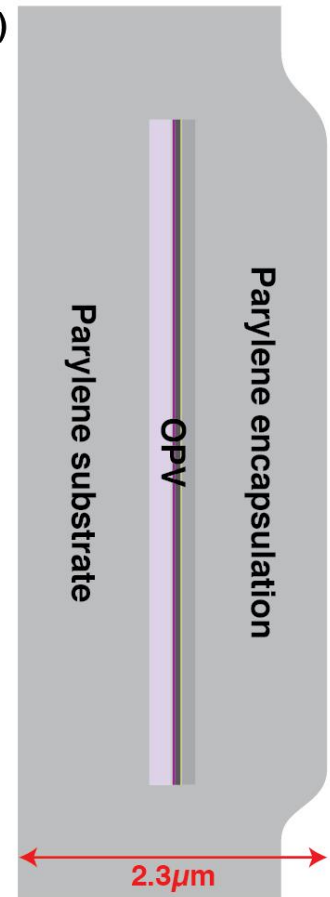

Fig. 3: Device structure and operation. (a) Schematic of molecular organic PV on $1 \mu \mathrm{m}$-thick parylene substrate, with all layer thicknesses except parylene shown to scale. (b) Nominal energy band diagram, with highest occupied and lowest unoccupied molecular orbital (HOMO/LUMO) energy levels shown for the donor (DBP), acceptor $\left(C_{60}\right)$, and interface buffer $(B C P)$, all referenced to the vacuum level. ${ }^{30}(c)$ Picture of released OPV on parylene. A frame is used to release and handle thin parylene films. (d) Free-standing parylene-based solar cells weigh only $0.36 \mathrm{mg} / \mathrm{cm}^{2}\left(3.6 \mathrm{~g} / \mathrm{m}^{2}\right)$ and can be supported by a suspended soap film. (e) Crosssectional schematic of encapsulated OPV on parylene, with thicknesses shown to scale.

Completed devices on parylene are released from the glass carrier by solvent-free, roomtemperature delamination. Thick parylene films are released easily from untreated silicon or glass, ${ }^{32}$ but thinner films often require sacrificial release layers ${ }^{33}$ such as the soluble layers used for parylene-based electronics. ${ }^{18,34}$ In this work, glass carriers are coated with dilute detergent prior to parylene deposition to reduce adhesion and facilitate dry release. Plastic frames cut from $3 \mathrm{M}$ transparency film and coated with double-sided adhesive are used to peel off and handle ultra-thin parylene membranes. The membranes are attached to the frames only at the perimeter, leaving the active devices free-standing. With this method, we have successfully released submicron-thick parylene films of up to 4" (100 mm) diameter (Fig. S1, SI) and expect no limit on substrate size.

Fig. 4 compares the performance of OPV devices on glass and on $1 \mu \mathrm{m}$-thick parylene-C substrates. Parylene- and glass-based devices perform similarly, with average short-circuit current densities $\left(\mathrm{J}_{\mathrm{SC}}\right)$ of $3.9 \mathrm{~mA} / \mathrm{cm}^{2}$ and $4.3 \mathrm{~mA} / \mathrm{cm}^{2}$, open-circuit voltages $\left(\mathrm{V}_{\mathrm{OC}}\right)$ of $0.87 \mathrm{~V}$ and $0.95 \mathrm{~V}$, fill factors (FF) of 0.64 and 0.58 , and power conversion efficiencies (PCE) of $2.2 \%$ and $2.3 \%$, respectively. The resulting mass per area of $3.6 \mathrm{~g} / \mathrm{m}^{2}$ for parylene-based OPV gives a specific power of $6.2 \mathrm{~W} / \mathrm{g}$, among the highest reported to date. ${ }^{3}$ Integration of $\mathrm{EQE}$ weighted by the solar photon flux predicts short-circuit current densities of $5.4 \mathrm{~mA} / \mathrm{cm}^{2}$ and $5.6 \mathrm{~mA} / \mathrm{cm}^{2}$ for parylene and glass-based devices, respectively. These calculated $\mathrm{J}_{\mathrm{SC}}$ values are higher than the 
measured values by 30-40\%, consistent with the expected spectral mismatch error from use of an unfiltered Si reference cell for light-source calibration in testing of organic solar cells. ${ }^{35} \mathrm{We}$ note that the discrepancy is consistent between parylene- and glass-based cells and thus does not affect the conclusions drawn herein.
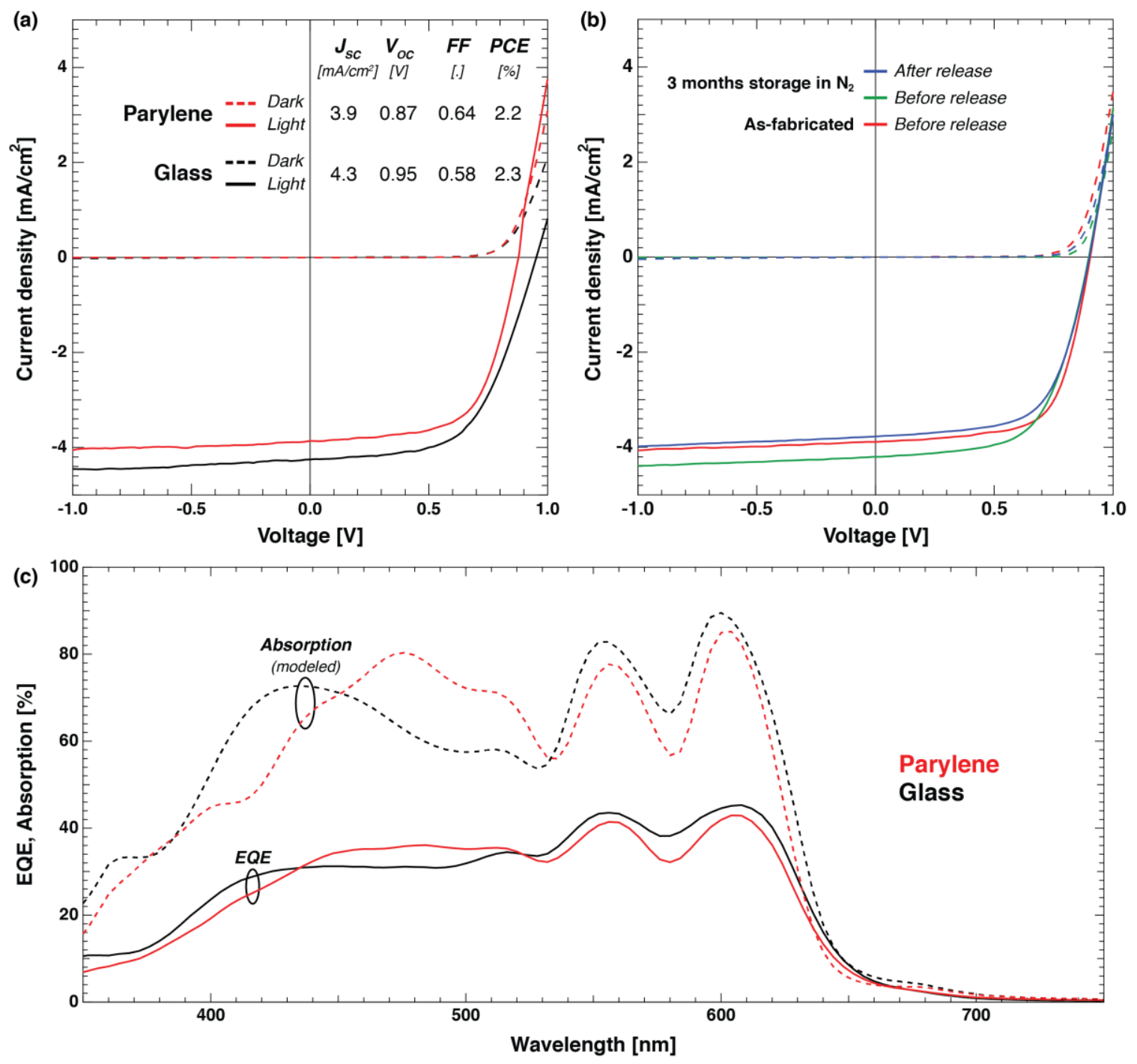

Fig. 4: Performance comparison of molecular organic solar cells on parylene-C and on glass substrates. (a) Current density-voltage characteristics in dark and under AM1.5G illumination. Glass- and parylene-based devices show similar power conversion efficiencies. (b) Effect of storage time and parylene release on PV performance. Devices stored in nitrogen for 3 months show minimal change in performance. Release of parylene-based cells reduces the measured photocurrent by $\sim 10 \%$, due to increased reflection loss from wrinkling of the parylene film. $(c)$ EQE and modeled absorption in active layers (DBP and $\left.C_{60}\right)$.

Parylene-based devices were tested in inert atmosphere immediately after fabrication (prior to release from the glass carrier), then released and laminated onto glass for further testing. The $10 \%$ reduction in current density after release (Fig. 4 b) can be attributed to increased reflection loss due to substrate wrinkling, which persists upon lamination. Air exposure and mechanical 
strain encountered during release did not degrade cell performance. Cells tested after 3 months of storage in nitrogen showed minimal degradation.

Optical modeling of complete devices and individual films was performed by the transfer-matrix

method. ${ }^{36,37}$ Complex optical constants were determined by fitting spectroscopic ellipsometry data, in some cases simultaneously with UV-vis transmittance measurements (Fig. S6, SI). Modeled absorption spectra for the active layers elucidate minor differences in the EQE spectra of devices on parylene and on glass (Fig. 4c). Electric field intensity profiles and absorption spectra for all layers are shown in the SI (Fig. S3-S5).

\section{Discussion}

Parylene substrates may be suitable for roll-to-roll processing of emerging thin-film solar cells. Manufacturing would entail deposition of parylene on a flexible carrier (e.g., planarized PET), followed by active layers and an additional encapsulation layer (Fig. S11, SI). The entire device stack could be peeled off and laminated onto another surface, leaving the carrier roll clean for reuse. Since in-situ-grown substrates do not require extra cleaning or mounting steps, handling of extremely thin substrates is simplified. Alternatively, parylene can be deposited as a buffer on a variety of common surfaces at room temperature to make them appear chemically identical.

Commercial experience suggests that vapor-phase deposition techniques can achieve roll-to-roll web speeds of up to $\sim 3 \mathrm{~m} / \mathrm{s}$, comparable to solution-based methods, which could help facilitate the deployment of low-cost, disposable solar cells.

Thin, flexible substrates must withstand environmental stresses during both processing and deployment. Hence, thermal and mechanical robustness, chemical compatibility, and UV stability are important considerations. Like most polymers, parylene-C is constrained to relatively low temperatures during processing. While the organic solar cells in this work are fabricated entirely at room temperature, other thin-film devices may require high-temperature processing. Co-deposition with an antioxidant can increase parylene's high-temperature stability in air to 1 hour at $200^{\circ} \mathrm{C},{ }^{15}$ sufficient for short processing steps. Typical PV operating temperatures of $\sim 50^{\circ} \mathrm{C}$ are easily survivable: Parylene-C is expected to endure 100,000 hours (11 years) of continuous use at $72^{\circ} \mathrm{C}$ in air and at $220^{\circ} \mathrm{C}$ in an oxygen-free environment. ${ }^{15}$

Sub-micron substrates are intrinsically fragile and difficult to handle. We have released parylene films as thin as $215 \mathrm{~nm}$, although such films tear easily. Compared to ultra-thin freestanding PET and PEN films that typically must be laminated to a carrier for processing and handling, parylene when directly deposited is intrinsically smooth and wrinkle-free, with no change in handling required for films of different thicknesses. We note that practical PV applications are likely to employ films at least several microns thick. Flexibility was not quantified in this study, although the performance of parylene-based OPV was not affected by the sharp bending angles encountered during release.

Although parylene is resistant to attack by nearly all acids, bases, and organic solvents, further work is needed to determine if it is compatible with various solution processing techniques. Films may swell and roughen upon exposure to certain solvents, though no permanent damage 
has been observed. ${ }^{38}$ In addition, parylene-C absorbs at wavelengths below $\lambda=290 \mathrm{~nm}$ (Fig. S2, SI) and can suffer from UV photodegradation in the presence of oxygen. UV exposure induces defects that deteriorate thermal stability and dielectric performance, potentially limiting unprotected use in outdoor and space applications. ${ }^{15,39}$ More-robust parylene variants could be engineered; for example, fluorinated variants can achieve much higher thermal and UV stability. For some applications (e.g., building-integrated PV), UV exposure can be avoided by laminating cells directly onto UV-absorbing glass. Furthermore, parylene substrates and encapsulants could be enhanced by coating before or after release with UV-blocking films (e.g., $\mathrm{CeO}_{2}$ ) and other functional layers (e.g., optical downconverters or dyes doped into parylene ${ }^{40}$ ) (Fig. S12, SI).

To be viable for solar applications, parylene must reach low material and processing costs. A $10 \%$ efficient solar cell on glass $\left(5 \$ / \mathrm{m}^{2}\right)$ incurs a substrate cost of $0.05 \$ / \mathrm{W}_{\mathrm{p}}$ - not insignificant compared to current c-Si PV module prices of $0.55-0.72 \$ / \mathrm{W}_{\mathrm{p}}{ }^{41}$ Raw material costs of parylene$\mathrm{C}$ are likely not prohibitive, with our estimates ranging from $14 \$ / \mathrm{m}^{2}$ at the lab scale to below 1 $\$ / \mathrm{m}^{2}$ at larger scale, assuming dimer price reduction and higher materials utilization (Fig. S13, SI). Indeed, in-situ-deposited parylene may be the lowest-cost option among ultra-thin $(\leq 5 \mu \mathrm{m})$ and flexible substrates, given quoted prices of $230 \$ / \mathrm{m}^{2}$ to $1290 \$ / \mathrm{m}^{2}$ for the largest PET and PEN films of $500 \mathrm{~nm}$ to $3 \mu \mathrm{m}$ thickness available from a leading supplier.

\section{Conclusions}

In conclusion, we have demonstrated in situ vapor-deposited parylene substrates for ultra-thin and lightweight organic solar cells, with specific powers exceeding $6 \mathrm{~W} / \mathrm{g}$. This work introduces a novel in-line method for PV substrate formation and illustrates the lower limit of practical substrate thickness and weight. Vacuum processing minimizes contamination and damage risk associated with transportation and handling of ultra-thin substrates. Organic PV cells on parylene exhibit efficiencies and fabrication yields comparable to cells on glass. Parylene-based solar cells can be laminated to provide additive solar power on a variety of solid surfaces.

\section{Acknowledgements}

We thank Andrea Maurano, Jill Macko, Patrick Brown, and Melany Sponseller for valuable discussions on device fabrication, testing, and analysis, Apoorva Murarka for assistance with parylene release, Anna Osherov for assistance with photography, and Dave Borrelli, Sunghwan Lee, Rachel Howden, Rong Yang, Nan Chen, and Karen Gleason for advice on CVD. We acknowledge funding from Eni S.p.A. via the Eni-MIT Solar Frontiers Center. JJ gratefully acknowledges financial support from the National Science Foundation. 


\section{References}

${ }^{1}$ J. Jean, P. R. Brown, R. L. Jaffe, T. Buonassisi and V. Bulović, Energy Environ. Sci. 2015, 8, 1200.

${ }^{2}$ MIT Future of Solar Energy Study, http://mitei.mit.edu/futureofsolar, (accessed May 2015).

${ }^{3}$ M. Kaltenbrunner, M. S. White, E. D. Głowacki, T. Sekitani, T. Someya, N. S. Sariciftci and S. Bauer, Nat. Commun. 2012, 3, 1.

${ }^{4}$ F. C. Krebs, Org. Electron. 2009, 10, 761.

${ }^{5}$ B. O’Connor, K. P. Pipe and M. Shtein, Appl. Phys. Lett. 2008, 92, 193306.

${ }^{6}$ M. C. Barr, J. A. Rowehl, R. R. Lunt, J. Xu, A. Wang, C. M. Boyce, S. G. Im, V. Bulović and K. K. Gleason, Adv. Mater. 2011, 23, 3500.

${ }^{7}$ M. C. Barr, R. M. Howden, R. R. Lunt, V. Bulović and K. K. Gleason, Adv. Energy Mater. 2012, 2, 1404.

${ }^{8}$ L. Leonat, M. S. White, E. D. Głowacki, M. C. Scharber, T. Zillger, J. Rühling, A. Hübler and N. S. Sariciftci, J. Phys. Chem. C 2014, 118, 16813.

${ }^{9}$ L. Hu, G. Zheng, J. Yao, N. Liu, B. Weil, M. Eskilsson, E. Karabulut, Z. Ruan, S. Fan, J. T.

Bloking, M. D. McGehee, L. Wågberg and Y. Cui, Energy Environ. Sci. 2013, 6, 513.

${ }^{10}$ Y. Zhou, C. Fuentes-Hernandez, T. M. Khan, J.-C. Liu, J. Hsu, J. W. Shim, A. Dindar, J. P. Youngblood, R. J. Moon and B. Kippelen, Sci. Rep. 2013, 3, 1536.

${ }^{11}$ W. A. MacDonald, J. Mater. Chem. 2004, 14, 4.

${ }^{12}$ W. A. MacDonald, M. K. Looney, D. MacKerron, R. Eveson, R. Adam, K. Hashimoto and K. Rakos, J. Soc. Inf. Disp. 2007, 15, 1075.

${ }^{13}$ S. R. Forrest, Chem. Rev. 1997, 97, 1793.

${ }^{14}$ M. E. Alf, A. Asatekin, M. C. Barr, S. H. Baxamusa, H. Chelawat, G. Ozaydin-Ince, C. D.

Petruczok, R. Sreenivasan, W. E. Tenhaeff, N. J. Trujillo, S. Vaddiraju, J. Xu and K. K. Gleason, Adv. Mater. 2010, 22, 1993.

${ }^{15}$ J. B. Fortin and T.-M. Lu, Chemical vapor deposition polymerization: The growth and properties of parylene thin films, Kluwer, Norwell, MA, USA 2003.

${ }^{16}$ M. A. Spivack and G. Ferrante, J. Electrochem. Soc. 1969, 116, 1592.

${ }^{17}$ T. A. Harder, T.-J. Yao, Q. He, C-Y. Shih and Y.-C. Tai, IEEE Int. Conf. Micro Electro Mech. Syst., Tech. Dig, $15^{\text {th }} \mathbf{2 0 0 2}, 435$.

${ }^{18}$ D. C. Rodger, A. J. Fong, W. Li, H. Ameri, A. K. Ahuja, C. Gutierrez, I. Lavrov, H. Zhong, P. R. Menon, E. Meng, J. W. Burdick, R. R. Roy, V. R. Edgerton, J. D. Weiland, M. S. Humayun and Y.-C. Tai, Sens. Actuators, B 2008, 132, 449.

${ }^{19}$ M. Szwarc, Polym. Eng. Sci. 1976, 16, 473.

${ }^{20}$ W. F. Gorham, J. Polym. Sci. Part A-1 Polym. Chem. 1966, 4, 3027.

${ }^{21}$ J. B. Fortin and T.-M. Lu, Chem. Mater. 2002, 14, 1945.

${ }^{22}$ C.-C. Lee, Y.-Y. Chang, H.-C. Cheng, J.-C. Ho and J. Chen, SID Symposium Digest of Technical Papers 2010, 41, 810.

${ }^{23}$ T. Yamamura, M. Kitamura, K. Kuribayashi, Y. Arakawa and S. Takeuchi, IEEE Int. Conf. Micro Electro Mech. Syst., Tech. Digest, 20th 2007, 739.

${ }^{24}$ Z. Chen, B. Cotterell and W. Wang, Eng. Fract. Mech. 2002, 69, 597.

${ }^{25}$ Y. Leterrier, L. Médico, F. Demarco, J.-A. E. Månson, U. Betz, M. F. Escolà, M. Kharrazi Olsson and F. Atamny, Thin Solid Films 2004, 460, 156. 
${ }^{26}$ T. Sasabayashi, N. Ito, E. Nishimura, M. Kon, P. K. Song, K. Utsumi, A. Kaijo and Y. Shigesato, Thin Solid Films 2003, 445, 219.

${ }^{27}$ H. Windischmann, Crit. Rev. Solid State Mater. Sci. 1992, 17, 547.

${ }^{28}$ E. Fortunato, D. Ginley, H. Hosono and D. C. Paine, MRS Bull. 2007, 32, 242.

${ }^{29}$ D. C. Paine, B. Yaglioglu, Z. Beiley and S. Lee, Thin Solid Films 2008, 516, 5894.

${ }^{30}$ D. Fujishima, H. Kanno, T. Kinoshita, E. Maruyama, M. Tanaka, M. Shirakawa and K. Shibata, Sol. Energy Mater. Sol. Cells 2009, 93, 1029.

${ }^{31}$ J. A. Macko, R. R. Lunt, T. P. Osedach, P. R. Brown, M. C. Barr, K. K. Gleason and V. Bulović, Phys. Chem. Chem. Phys. 2012, 14, 14548.

${ }^{32}$ S. Takeuchi, D. Ziegler, Y. Yoshida, K. Mabuchi and T. Suzuki, Lab Chip 2005, 5, 519.

${ }^{33}$ D. Ziegler, T. Suzuki and S. Takeuchi, J. Microelectromech. Syst. 2006, 15, 1477.

${ }^{34}$ G. A. Salvatore, N. Münzenrieder, T. Kinkeldei, L. Petti, C. Zysset, I. Strebel, L. Büthe and G. Tröster, Nat. Commun. 2014, 5, 2982.

${ }^{35}$ V. Shrotriya, G. Li, Y. Yao, T. Moriarty, K. Emery and Y. Yang, Adv. Funct. Mater. 2006, 16, 2016.

${ }^{36}$ L. A. A. Pettersson, L. S. Roman and O. Inganäs, J. Appl. Phys. 1999, 86, 487.

${ }^{37}$ P. Peumans, A. Yakimov and S. R. Forrest, J. Appl. Phys. 2003, 93, 3693.

${ }^{38}$ H. C. Koydemir, H. Kulah and C. Ozgen, J. Microelectromech. Syst. 2014, 23, 298.

39 J. B. Fortin and T.-M. Lu, Thin Solid Films 2001, 397, 223.

${ }^{40}$ G. Maggioni, A. Campagnaro, S. Carturan and A. Quaranta, Sol. Energy Mater. Sol. Cells 2013, 108, 27.

${ }^{41}$ Module Price Index, pvXchange, http://www.pvxchange.com, (accessed August 2015). 
Parylene

Solar cell

\author{
Parylene
}

